\title{
Comparison of injuries sustained on artificial turf and grass by male and female elite football players
}

Jan Ekstrand, Martin Hägglund and C.W Fuller

\section{Linköping University Post Print}

N.B.: When citing this work, cite the original article.

This is the authors' version of the final publication:

Jan Ekstrand, Martin Hägglund and C.W Fuller, Comparison of injuries sustained on artificial turf and grass by male and female elite football players, 2011, Scandinavian Journal of Medicine and Science in Sports, (21), 6, 824-832.

http://dx.doi.org/10.1111/j.1600-0838.2010.01118.x

Copyright: John Wiley and Sons http://www.wiley.com/

Postprint available at: Linköping University Electronic Press

http://urn.kb.se/resolve?urn=urn:nbn:se:liu:diva-67089 


\title{
Comparison of injuries sustained on artificial turf and grass by male and female elite football players
}

\author{
J. Ekstrand ${ }^{1}$, M. Hägglund ${ }^{1}$, C W Fuller ${ }^{2}$ \\ ${ }^{1}$ Department of Medical and Health Sciences, Linköping University, Linköping, Sweden \\ ${ }^{2}$ Centre for Sports Medicine, University of Nottingham, Nottingham, UK
}

Correspondence should be addressed to:

Professor Jan Ekstrand, MD, PhD

Address: Solstigen 3, 58943 Linköping, Sweden

Phone: +4613161648

Fax: +4613161892

E-mail: jan.ekstrand@telia.com

Running head: Playing elite level football on artificial turf

Key words: injury incidence, epidemiology, soccer 
Playing elite level football on artificial turf

\section{ABSTRACT}

The objective was to compare incidences and patterns of injury for female and male elite teams when playing football on artificial turf and grass.

Twenty teams (15 male, 5 female) playing home matches on third generation artificial turf were followed prospectively; their injury risk when playing on artificial turf pitches was compared to the risk when playing on grass. Individual exposure, injuries (time loss) and injury severity were recorded by the team medical staff.

In total, 2105 injuries were recorded during 246000 hours of exposure to football. Seventyone percent of the injuries were traumatic and $29 \%$ overuse injuries. There were no significant differences in the nature of overuse injuries recorded on artificial turf and grass for either men or women.

The incidence (injuries/1000 player-hours) of acute (traumatic) injuries did not differ significantly between artificial turf and grass, for men (match 22.4 v 21.7; RR 1.0 (95\% CI 0.9-1.2); training 3.5 v 3.5; RR $1.0(0.8-1.2)$ ) or women (match 14.9 v 12.5; RR 1.2 (0.8-1.8); training 2.9 v 2.8; RR $1.0(0.6-1.7))$. During matches, men were less likely to sustain a quadriceps strain $(\mathrm{p}=0.031)$ and more likely to sustain an ankle sprain $(\mathrm{p}=0.040)$ on artificial turf. 
Playing elite level football on artificial turf

\section{INTRODUCTION}

The latest generation of artificial turf surfaces is increasingly being installed and used within European football. These new pitches offer football-specific features that are similar to those found with well-maintained natural turf pitches. Consequently, FIFA (Fédération Internationale de Football Associations) in 2004 decided that matches may be played on artificial surfaces, according to the rules of the competition. The Laws of the game (FIFA 2009) state: "Where artificial surfaces are used in either competition matches between representative teams of member associations affiliated to FIFA or international club competition matches, the surface must meet the requirements of the FIFA Quality Concept for Artificial Turf or the International Artificial Turf Standard, unless special dispensation is given by FIFA“. The FIFA Quality Concept is an evaluation programme with laboratory and field tests aiming to set high quality standards and criteria for artificial surfaces. FIFA and UEFA have introduced the terminology of "football turf " for artificial turf pitches meeting the criteria of the FIFA Quality Concept criteria.

Playing football on the older generations of artificial surfaces had disadvantages; for example, they changed the performance characteristics and the injury pattern of the sport (Nigg \& Yeadon, 1987; Ekstrand \& Nigg, 1989). The few reports comparing the injury risk from playing football on the earlier generations of artificial turf with natural grass showed an increased injury risk and a different injury pattern when playing on artificial turf pitches (Hort, 1977; Renström et al., 1977; Engebretsen \& Kase, 1987; Árnason et al. 1996) .

The negative experiences of players and spectators gained from the first two generations led to the development of a third-generation artificial turf that was designed specifically for football. These third generation artificial turfs were made of longer $(>40 \mathrm{~mm})$ and more spread polypropylene or polyethylene fibres in-filled with rubber granules. 
Playing elite level football on artificial turf

Despite the wide use of football turf pitches by non-elite players and despite their obvious advantages such as increased pitch utility and the possibility of providing a good year-round quality pitch irrespective of climate conditions, acceptance is limited by elite teams. One reason for this might simply be that the negative views developed from the adverse experiences of earlier generations of artificial turf pitches are being perpetuated.

Even though third generation football turfs have been available for a number of years, there are few studies evaluating the injury risk and injury patterns on these surfaces. Ekstrand et al. (2006) studied male professional players in Europe and found that the risk of injury was similar when playing on artificial turf and natural grass. Fuller et al. (2007a,b) found no major differences in the incidence, severity and nature of injuries when studying male and female amateur players from colleges and universities in USA. Steffen et al. (2007), studied young female players in Norway and found a similar risk of acute injuries on artificial turf as on grass.

It is established that on grass surfaces the incidence and pattern of injury among elite female players are slightly different from those of elite male (Junge \& Dvorak, 2007; Hägglund et al., 2008). However, to our knowledge, there are no studies evaluating the incidence and pattern of injury for female elite players on artificial turf and no studies comparing the risks of injury with those for male professional players using the same study design.

The aims of this study were to compare the incidences and injury patterns of female and male elite teams when training and playing matches on artificial turf and natural grass. 
Playing elite level football on artificial turf

\section{MATERIALS AND METHODS}

\section{Study period and participants}

A prospective cohort study of elite level male and female teams playing home games on artificial turf and away games on artificial turf and grass was carried out from February 2003 to October 2008.

25 elite teams (19 male and 6 female teams) that had reported the installation of a third generation artificial turf pitch to UEFA were invited to participate. UEFA defines elite level football as the two highest national football leagues for males and the highest league for females. In total, twenty teams (15 male and 5 female teams) accepted the invitation to participate and delivered a complete set of data; details of these teams are shown in Table 1.

All players in the first team squads were invited to take part in the study: in total, 767 (613 male and 154 female) players were included. Anthropometric data for these players are shown in Table 2. Exposure and injury data for players that left the study (due to transfer or other reasons) were included for their time of participation. The players were informed about the study and accepted participation by signing an informed consent form.

\section{Study procedure and validity}

The development and validation of the protocols and methodology used in the present study have been described previously (Hägglund et al., 2005). The definitions and data collection procedures used follow the recommendations of the consensus statement for football injury studies (Fuller et al., 2006). The definitions applied in the study are shown in Table 3. All injuries resulting in the player being unable to fully participate in training or match play (i.e. time loss injuries) were recorded, and the player was considered injured until the team medical staff allowed full participation in training and availability for match selection. Injuries were categorized into five degrees of severity based on the number of days absent 
Playing elite level football on artificial turf

(Table 3). All injuries were followed until the final day of rehabilitation. If a player was injured when entering into the study, that injury was not included.

To reduce bias and inconsistencies in data collection, all clubs were provided with a manual containing information about the study design and definitions together with explanatory examples and scenarios. Report forms were sent to the study group on a monthly basis, and clubs were provided with regular feedback to improve accuracy and consistency in reporting. Player exposure and surface type were registered for all training sessions and matches (including matches with national teams and reserve teams) on a standard exposure form (Hägglund et al., 2005) by a member of the squad, who was present at all training sessions and matches. The team medical staff recorded all injuries on a standard injury form (Hägglund et al., 2005) immediately after the event.

Sample size calculations using a size effect of $50 \%$, power of $90 \%$ and confidence level of $95 \%$ showed that, based on match incidences of 25 injuries/1000 player-hours for male and 20 injuries/1000 player-hours for female players, 4200 player-match hours for men and 5250 player-match hours for women were required on both surfaces to identify significant differences. Using the same criteria but based on a training incidence of 4 injuries/1000 player-hours for male and female players, calculations showed that 26000 player-training hours were required on each surface for both groups to identify statistically significant results. The study protocol was approved by the ethics committee of Linköping University, Sweden (D-nr 73/04) and the total study design was approved by FIFA and UEFA.

\section{Analyses}

Outcome measures were injury incidences (injuries/1000 hours of exposure) and time lost from training and match play. For analyses, injury incidences for artificial turf surfaces were 
Playing elite level football on artificial turf

aggregated and compared with aggregated data for grass surfaces. Injury incidences were compared between groups using rate ratios (95\% confidence intervals). Due to the number of comparisons made in this study, a significance level of $\mathrm{p}<0.01$ was considered appropriate.

\section{RESULTS}

\section{Exposure}

Male teams registered a total of 143571 hours of exposure on artificial turf (126 272 training and 17299 match play) and 54500 hours on grass (40 921 training and 13579 match play). In addition, 20194 hours on other surfaces (20 105 training and 89 match play) were recorded. Female teams documented 38555 hours of exposure on artificial turf (34 053 training and 4502 match play), 9849 hours on grass (6 811 training and 3038 match play) and 7052 hours on other surfaces, all in training. Thus, the relative amount of exposure on artificial turf (of overall exposure) was $66 \%$ for males (68\% training and $56 \%$ match play) and $69 \%$ for females (71\% training and $55 \%$ match play). Injuries and exposure on other surfaces than artificial turf and natural grass were not included in the analyses.

\section{Injuries}

A total of 2105 injuries were recorded, of which 1791 were sustained by male and 314 by female players. Seventy-one percent of the injuries were traumatic and $29 \%$ due to overuse (tendinopathies, bursitis, synovitis and other unspecified overuse complaints) for both males and females. On average, male teams in the study incurred 50 injuries in a season, which corresponded to approximately 2 injuries/player/season, and female teams about 30 injuries in a season, which corresponded to approximately 1-2 injuries/player/season. 
Playing elite level football on artificial turf

There were no significant differences in the nature of overuse injuries recorded on artificial turf and grass for either men or women. The incidences of the most common types of overuse injuries are presented as a function of total exposure (training and competition) in Fig.1. For the following analyses only traumatic injuries were included as overuse injuries have a gradual onset, making it difficult to identify the surface or the activity in which the injury was initiated.

\section{Injury incidence and severity}

Incidences of injury for male and female players on artificial turf and grass are presented in Table 4 as function of injury severity. This analysis showed no significant differences in the overall incidence of injury between the surfaces during training or match play for either males or females. There were also no significant differences between artificial turf and grass when the incidences were compared in terms of injury severity sub-categories.

\section{Nature of injury}

We did not find any significant differences in the incidence of injury as a function of body location (Table 5). The majority of injuries affected the lower limb; for males, $86 \%$ on grass and $87 \%$ on artificial turf, for females, $81 \%$ on grass and $87 \%$ on artificial turf. For males, the thigh was the most common injury location both on training and matches, while for women, thigh and knee injuries were the most common on matches and thigh and ankle on training. When analysing the incidence of injury as a function of injury type (Table 6), the incidence of muscle rupture/strains in matches for males were lower on artificial turf than on grass but the difference did not reach significance $(\mathrm{p}=0.020)$.

Table 7 presents the incidences of the most common traumatic injury subtypes. Ankle sprains and hamstring strains were the most common injury subtypes for males and females during 
Playing elite level football on artificial turf

matches and training on both artificial turf and grass. During matches, the risk of men sustaining a quadriceps strain was lower $(\mathrm{p}=0.031)$ and the risk of sustaining an ankle sprain higher $(\mathrm{p}=0.040)$ on artificial turf compared to grass. During training, men were more likely $(\mathrm{p}=0.016)$ to sustain a calf strain on grass than artificial turf. Overall few lacerations/skin lesions $(0.4 \%$ of all injuries) were seen during matches or training.

\section{DISCUSSION}

The principal finding in this study was that the injury risk, for both male and female elite players, is not changed significantly when playing football on third-generation artificial turf surfaces compared to playing on natural grass. The overall injury incidences were similar on the two surfaces and the incidences of injury during training and match play found in the present study are comparable to other studies of elite level football in Europe (Árnason et al., 1996; Hawkins et al., 2001; Andersen et al. 2004; Ekstrand et al., 2004; Hägglund et al., 2005, 2008; Walden et al., 2005; Ekstrand, 2008; Ekstrand et al., 2009; Walden et al., 2007). The finding of this study tallies with other studies comparing the injury risk when playing football on third-generation artificial turf pitches compared to playing on natural grass; Ekstrand et al. (2006) found similar results when studying male elite level teams, Fuller et al. (2007a,b) when studying male and female college and university teams and Steffen et al. (2007) when studying female youth teams.

For the analysis of injury incidence on artificial turf compared with natural grass, only traumatic injuries with an acute onset were included in the calculations because it is difficult to identify the initiating cause of an overuse injury. The proportion of overuse/gradual onset injuries in the present study was $29 \%$ for both men and women, whereas in a previous study of non-elite male and female players (Fuller et al., 2007a,b) the proportions were significantly 
Playing elite level football on artificial turf

lower for both men $(7.6 \% ; \mathrm{p}<0.001)$ and women $(11.5 \%$; $<<0.001)$. While the ratios of training to match play in both studies were similar, the seasonal exposure of players in the present study was very much higher and this will undoubtedly contribute to the higher number of overuse injuries observed in this study. Although the intensity of training and match play was not recorded in either study, one can speculate that the intensity at the elite level would be higher than at the non-elite level and this would also contribute to the reasons for the higher number of overuse injuries observed in this study.

This study used the time-loss definition of injuries since that captures the most relevant injuries; namely, those that directly influence the player's ability to take part in training and matches (Bahr, 2009). Even so, the proportion of overuse/gradual onset injuries in the present study was almost one-third for both men and women. Still, the problem with overuse can be underestimated in studies using the time-loss definition since players can chose to participate but not play to full capacity. However, the risk of underestimating the overuse problem is less likely in studies with an elite population since (due to competition in selection) players with overuse problems and reduced function are much less likely to be selected for matches. Further, becaue medical staffs at elite level are aware of the findings that negligence of minor injuries could lead to later severe injuries (Ekstrand \& Gillquist, 1983), they allow players with overuse symptoms to rest in order to avoid later aggravations.

Analysis of the incidence of injury as a function of injury type and location, identified no significant differences, although there was an indication that there may be a lower risk of muscle strains in matches on artificial turf for male players $(\mathrm{p}=0.020)$.

The analysis of the most common injury sub types during match play revealed no significant differences between playing surfaces but there were indications of a lowered injury risk for quadriceps strains $(\mathrm{p}=0.031)$ and a higher risk for ankle sprains $(\mathrm{p}=0.040)$ for men when playing on artificial turf. During training, there was an indication that men were more likely 
Playing elite level football on artificial turf

to sustain calf muscle strains on grass than artificial turf $(\mathrm{p}=0.016)$. However, due to the limited dataset these differences did not reach statistical significance. Similar findings of a lower risk of muscle strains and a higher risk of ankle sprains on artificial turf were previously reported by Ekstrand et al. (2006) when studying male elite players, but this difference was not observed by Fuller et al. (2007a,b) when studying male and female college and university players or by Steffen et al. (2007) when studying young female players. The differences should be interpreted with caution due to the possibility of a type II error due to the small numbers, but it may well be that the risk of muscle strain differs in different populations, e.g. in different age groups, different countries or in different playing circumstances. The most common injuries reported in this study of elite players are similar to those reported by Fuller et al. (2007a,b) for non-elite players with the exception of concussions. Although the incidences of concussion reported for women were higher than those reported for men on both surfaces in both studies, the incidences of concussion observed in the present study were generally 25 to $50 \%$ lower than those reported previously for non-elite players. These results support the conclusion that women exhibit higher rates of concussion in sport (Dick, 2009) but they may also indicate a real difference in the incidence of concussion in football between elite and non-elite players, due to a reluctance by elite players to report this type of injury or a more conservative approach to concussion treatment amongst non-elite players.

The male cohort in the present study is a fairly homogenous group of elite level players. Further, as seen in Table 1, the majority of the male teams played their home matches on high quality artificial turf pitches, most of them with a one or two star FIFA Quality licence. Teams playing on lower quality artificial turf pitches might have a different injury pattern. Wounds, burns and friction injuries have been reported to be more frequent when playing on earlier generations of artificial turf pitches (Renström et al,1977; Gaulrapp et al., 1999). In the 
Playing elite level football on artificial turf

present study, 22 skin abrasions were reported, which amounts to only $0.4 \%$ of all injuries. Burns and frictions might therefore not be a problem when playing on modern high quality artificial turf pitches. For a FIFA licence, a yearly mandatory assessment of surface friction is required and the results must be within certain limits; however, one should also note that only time-loss injuries were recorded in the present study.

\section{Methodological considerations}

The collection of data followed the international consensus agreements on procedures for epidemiological studies of football injuries recommended by FIFA and UEFA (Hägglund et al., 2005; Fuller et al., 2006). The obvious strength of this study is the homogenous material of elite level players in Europe. The cause of football injuries is multifactorial and there are many confounding risk factors to consider ( Meeuwisse, 1994_Bahr \& Holme 2003; Ekstrand et al. 2003;). An advantage with an intra-cohort design, as in the present study, is that the same teams were followed when playing their home matches on artificial turf and the majority of their away matches on natural grass, thus eliminating many of the confounding factors related to inter team differences, e.g. reporting variations and differences in climate. However, it is possible that team tactics may vary between home and away games and this could impact on the incidence and nature of injuries.

The reliability of recording of injuries is always a concern in epidemiological studies, especially when it comes to minimal and slight injuries. However, the teams in this study were elite level teams and the data was collected by experienced medical staffs (mainly doctors and physiotherapists), who would be expected to deliver data with a higher level of accuracy compared to studies at the amateur level. A number of measures were taken in this study to ensure that data were as complete and accurate as possible. For example, all participating teams were provided with a comprehensive study manual describing procedures, 
Playing elite level football on artificial turf

definitions etc. together with explanatory examples and scenarios. Further, all monthly reports were immediately reviewed by the study group and inaccuracies or incomplete registrations were identified and corrected with feedback sent to the contact persons in the appropriate clubs.

A weakness with the present study is the limited dataset obtained from the female clubs. For females, no differences were found between the risk of injury when playing on artificial turf and natural grass, neither for the overall injury risk nor when analysing location or type of injury or injury sub-types. A similar trend as for men, with an increased risk of ankle sprain on artificial turf was also seen among female players. However, due to the limited dataset this did not reach statistical significance. The risk of Type II errors must be considered. According to a sample size calculation (power $90 \%$ ) we would have needed 196000 hours of exposure on artificial turf and 130000 on grass in order to detect a statistically significant difference with the size effect of $25 \%$ as observed for match injury incidence between surfaces $(2.89 \mathrm{v}$ 2.30 ankle sprains/1000 match hours).

As in all prospective cohort studies, causal relationships between findings are difficult to establish. Our finding of a lower risk for the most common muscle strains when playing on artificial turf pitches needs to be evaluated for biological plausibility (Bradford-Hill, 1965) and needs consistence with similar findings in other studies. Movement analyses of matches played on high quality artificial turf pitches (pitches with a FIFA quality licence) and matches played on grass have not shown any significant differences in distances covered, sprints, number of passes etc (Andersson et al., 2008).

A hypothesis that different energy restitutions between artificial turf and grass might cause muscle fatigue and thus an increased risk of muscle injury, has to be evaluated in further studies of biomechanic surface properties in relation to injuries. 
Playing elite level football on artificial turf

\section{PERSPECTIVES}

As far as we know, there are only three studies that have analyzed the risk of injury when playing football on the third generation of artificial turf pitches compared to the risk when playing on natural grass (Ekstrand et al., 2006; Fuller et al., 2007,a,b; Steffen et al., 2007). All these studies found that there were no major differences in the overall injury risk between the two surfaces, neither in training nor in matches, neither in men nor in women and neither at adult elite level nor at amateur youth level. From a medical point of view, there was no contraindication to expansion of artificial turf technology.

However, there might be differences in the pattern of injury sustained on these two surface types. Indications of a lowered risk of muscle strains when playing on the new generation of artificial turf pitches compared to playing on natural grass, were found in the present study as well as a previous study of male elite level players (Ekstrand et al. 2006). The tendency to a higher risk of ankle sprain when playing on artificial turf was also found in a study of young female footballers (Steffen et al., 2007). These tendencies of a difference in injury pattern between the two types of surfaces need to be investigated further in studies with larger cohorts and a higher statistical power.

Even though the proportion of overuse/gradual onset injuries in the present study was $29 \%$, there is still a risk of underestimation of overuse injuries in studies using the time-loss definition. The concept of overuse problems needs to be evaluated further in contact sports like football.

\section{ACKNOWLEDGEMENTS}


Playing elite level football on artificial turf

We are grateful to all the club doctors and contact persons for collection of exposure and injury data. Henrik Magnusson is greatly acknowledged for statistical advice. This study was partially funded by UEFA, the Swedish Centre for Research in Sports and Praktikertjänst AB. 
Playing elite level football on artificial turf

Table 1. Details of the 20 included football teams who played on third-generation artificial surfaces

\begin{tabular}{|c|c|c|c|c|c|c|c|}
\hline Team & Country & Gender & Level of play $^{\text {a }}$ & $\begin{array}{l}\text { Months of } \\
\text { data } \\
\text { collection }\end{array}$ & $\begin{array}{l}\text { FIFA } \\
\text { licence }\end{array}$ & $\begin{array}{l}\text { Type of } \\
\text { artificial turf }\end{array}$ & Season \\
\hline Umeå IK & Sweden & $\mathrm{F}$ & $1^{\text {st }}$ division & 38 & $*$ & Desso & Spring - Autumn \\
\hline Hammarby IF DFF & Sweden & $\mathrm{F}$ & $1^{\text {st }}$ division & 39 & & Desso & Spring - Autumn \\
\hline KIF Örebro & Sweden & $\mathrm{F}$ & $1^{\text {st }}$ division & 22 & $* *$ & Mondoturf & Spring - Autumn \\
\hline Kopparbergs/Göteborg FC & Sweden & $\mathrm{F}$ & $1^{\text {st }}$ division & 8 & $* *$ & Fieldturf & Spring - Autumn \\
\hline AIK & Sweden & $\mathrm{F}$ & $1^{\text {st }}$ division & 10 & & Tarkett & Spring - Autumn \\
\hline Örebro SK & Sweden & M & $1^{\text {st }} / 2^{\text {nd }}$ division & 58 & $* *$ & Mondoturf & Spring - Autumn \\
\hline Heracles Almelo & Netherlands & M & $1^{\text {st }}$ division & 59 & $* *$ & Arcadis/Edelgras & Autumn - Spring \\
\hline HJK Helsinki & Finland & M & $1^{\text {st }}$ division & 52 & $* *$ & Mondoturf & Spring - Autumn \\
\hline GIF Sundsvall & Sweden & M & $2^{\text {nd }}$ division & 20 & & Fieldturf & Spring - Autumn \\
\hline IF Elfsborg & Sweden & M & $1^{\text {st }}$ division & 36 & $* *$ & Limonja & Spring - Autumn \\
\hline Gefle IF & Sweden & M & $1^{\text {st }}$ division & 43 & & Fieldturf & Spring - Autumn \\
\hline BSC Young Boys & Switzerland & M & $1^{\text {st }}$ division & 26 & $* *$ & Polytan & Autumn - Spring \\
\hline Dundalk FC & Ireland & M & $2^{\text {nd }}$ division & 6 & $* *$ & Fieldturf & Spring - Autumn \\
\hline Troms $\varnothing$ IL & Norway & M & $1^{\text {st }}$ division & 11 & $* *$ & Edel Grass & Spring - Autumn \\
\hline Neuchâtel Xamax FC & Switzerland & M & $1^{\text {st }}$ division & 9 & $* *$ & Polytan & Autumn - Spring \\
\hline Aalesunds FK & Norway & M & $1^{\text {st }}$ division & 10 & $*$ & Greenfields & Spring - Autumn \\
\hline SV Austria Salzburg & Austria & M & $1^{\text {st }}$ division & 4 & $* *$ & Polytan & Autumn - Spring \\
\hline Dunfermline Athletic FC & Scotland & M & $1^{\text {st }}$ division & 19 & & XL turf & Autumn - Spring \\
\hline Västra Frölunda IF & Sweden & M & $2^{\text {nd }}$ division & 19 & & Saltex & Spring - Autumn \\
\hline TUIL Tromsdalen & Norway & M & $2^{\text {nd }}$ division & 18 & & Astroplay & Spring - Autumn \\
\hline
\end{tabular}

${ }^{\text {a }} 1^{\text {st }}$ and $2^{\text {nd }}$ divisions being the two highest domestic leagues.

* Qualified for the FIFA recommended 1 star mark

** Qualified for the FIFA recommended 2 star mark 
Playing elite level football on artificial turf

Table 2. Anthropometric data for the 767 included players

\begin{tabular}{lrrrr}
\hline & \multicolumn{2}{c}{ Men $(\mathbf{n}=613)$} & \multicolumn{2}{c}{ Women $(\mathbf{n = 1 5 4})$} \\
& Mean \pm SD & $($ Range $)$ & Mean \pm SD & $($ Range $)$ \\
\hline Age (years) & $25 \pm 5$ & $(16-38)$ & $23 \pm 4$ & $(15-38)$ \\
Body mass $(\mathrm{kg})$ & $78 \pm 7$ & $(59-107)$ & $62 \pm 6$ & $(49-79)$ \\
Height $(\mathrm{cm})$ & $182 \pm 6$ & $(164-205)$ & $168 \pm 5$ & $(152-180)$ \\
\hline
\end{tabular}




\section{Playing elite level football on artificial turf}

\section{Table 3. Operational definitions}

Training session

Match

Injury

Rehabilitation

Re-injury

Slight injury

Minimal injury

Mild injury

Moderate injury

Severe injury

Traumatic injury

Overuse injury

Foul play injury

Injury incidence
Team training under the supervision of the coaching staff that involved physical activity.

Competitive or friendly match against another team.

Injury resulting from playing football and leading to a player being unable to fully participate in future training or match play (i.e. time loss injury).

A player was considered injured until team medical staff allowed full participation in training and availability for match selection.

Injury of the same type and at the same site as an index injury occurring within 2 months after a player's return to full participation from the index injury

Injury causing absence from training and match play for < 1 day.

Injury causing absence 1-3 days from training and match play.

Injury causing absence 4-7 days from training and match play.

Injury causing absence 8-28 days from training and match play.

Injury causing absence $>28$ days from training and match play.

Injury with sudden onset and known cause of event.

Injury with insidious onset and without any known trauma.

Match injury resulting from foul play according to the decision of the referee.

Number of injuries per 1000 player hours $[(\Sigma$ injuries $/ \Sigma$ exposure hours $) \times 1000]$ 
Playing elite level football on artificial turf

Table 4. Incidence and severity of acute injuries

\begin{tabular}{|c|c|c|c|c|c|c|c|c|c|c|c|c|}
\hline \multirow[b]{3}{*}{ TRAINING INJURIES } & \multicolumn{4}{|c|}{ Men } & \multicolumn{6}{|c|}{ Women } & \multirow[b]{3}{*}{$\mathrm{RR}$} & \multirow[b]{3}{*}{$(95 \% \mathrm{CI})$} \\
\hline & \multicolumn{2}{|c|}{ Art Turf } & \multicolumn{2}{|c|}{ Grass } & \multirow[b]{2}{*}{$\mathrm{RR}$} & \multirow[b]{2}{*}{$(95 \% \mathrm{CI})$} & \multicolumn{2}{|c|}{ Art Turf } & \multicolumn{2}{|c|}{ Grass } & & \\
\hline & $\mathrm{N}$ & Inc & $\mathrm{N}$ & Inc & & & $\mathrm{N}$ & Inc & $\mathrm{N}$ & Inc & & \\
\hline Slight & 10 & 0,08 & 2 & 0,05 & 1,62 & $(0,36$ to 7,40$)$ & 1 & 0,03 & 0 & 0,00 & NA & \\
\hline Minimal & 146 & 1,16 & 44 & 1,08 & 1,08 & $(0,77$ to 1,51$)$ & 27 & 0,79 & 6 & 0,88 & 0,90 & $(0,37$ to 2,18$)$ \\
\hline Mild & 101 & 0,80 & 36 & 0,88 & 0,91 & $(0,62$ to 1,33$)$ & 30 & 0,88 & 6 & 0,88 & 1,00 & $(0,42$ to 2,40$)$ \\
\hline Moderate & 137 & 1,08 & 40 & 0,98 & 1,11 & (0,78 to 1,58$)$ & 29 & 0,85 & 7 & 1,03 & 0,83 & (0,36 to 1,89$)$ \\
\hline Severe & 51 & 0,40 & 20 & 0,49 & 0,83 & $(0,49$ to 1,39$)$ & 12 & 0,35 & 0 & 0,00 & NA & \\
\hline Total & 445 & 3,52 & 142 & 3,47 & 1,02 & $(0,84$ to 1,23$)$ & 99 & 2,91 & 19 & 2,79 & 1,04 & $(0,64$ to 1,70$)$ \\
\hline MATCH INJURIES & $\mathrm{N}$ & Inc & $\mathrm{N}$ & Inc & $\mathrm{RR}$ & $(95 \% \mathrm{CI})$ & $\mathrm{N}$ & Inc & $\mathrm{N}$ & Inc & $\mathrm{RR}$ & $(95 \% \mathrm{CI})$ \\
\hline Slight & 15 & 0,87 & 2 & 0,15 & 5,89 & $(1,35$ to 25,74$)$ & 0 & 0,00 & 0 & 0,00 & NA & \\
\hline Minimal & 127 & 7,34 & 87 & 6,41 & 1,15 & $(0,87$ to 1,51$)$ & 22 & 4,89 & 12 & 3,95 & 1,24 & $(0,61$ to 2,50$)$ \\
\hline Mild & 106 & 6,13 & 84 & 6,19 & 0,99 & $(0,74$ to 1,32$)$ & 18 & 4,00 & 8 & 2,63 & 1,52 & $(0,66$ to 3,49$)$ \\
\hline Moderate & 105 & 6,07 & 90 & 6,63 & 0,92 & $(0,69$ to 1,21$)$ & 20 & 4,44 & 9 & 2,96 & 1,50 & $(0,68$ to 3,29$)$ \\
\hline Severe & 34 & 1,97 & 32 & 2,36 & 0,83 & $(0,51$ to 1,35$)$ & 7 & 1,55 & 9 & 2,96 & 0,52 & $(0,20$ to 1,41$)$ \\
\hline Total & 387 & 22,37 & 295 & 21,72 & 1,03 & $(0,89$ to 1,20$)$ & 67 & 14,88 & 38 & 12,51 & 1,19 & ( 0,80 to 1,77$)$ \\
\hline
\end{tabular}

RR: Rate Ratio

Men: 143571 hours on artificial turf (126 272 training and 17299 match play) and 54500 hours on grass (40 921 training and 13579 match

play)

Women: 38555 hours on artificial turf (34053 training and 4502 match play) and 9849 hours on grass (6 811 training and 3038 match play).

Overuse injuries $(522 / 1791=29 \%$ in men and $91 / 314=29 \%$ in women $)$ were excluded from the analysis. 
Playing elite level football on artificial turf

Table 5. Incidence of acute injuries (injuries/1000 hours) as a function of location

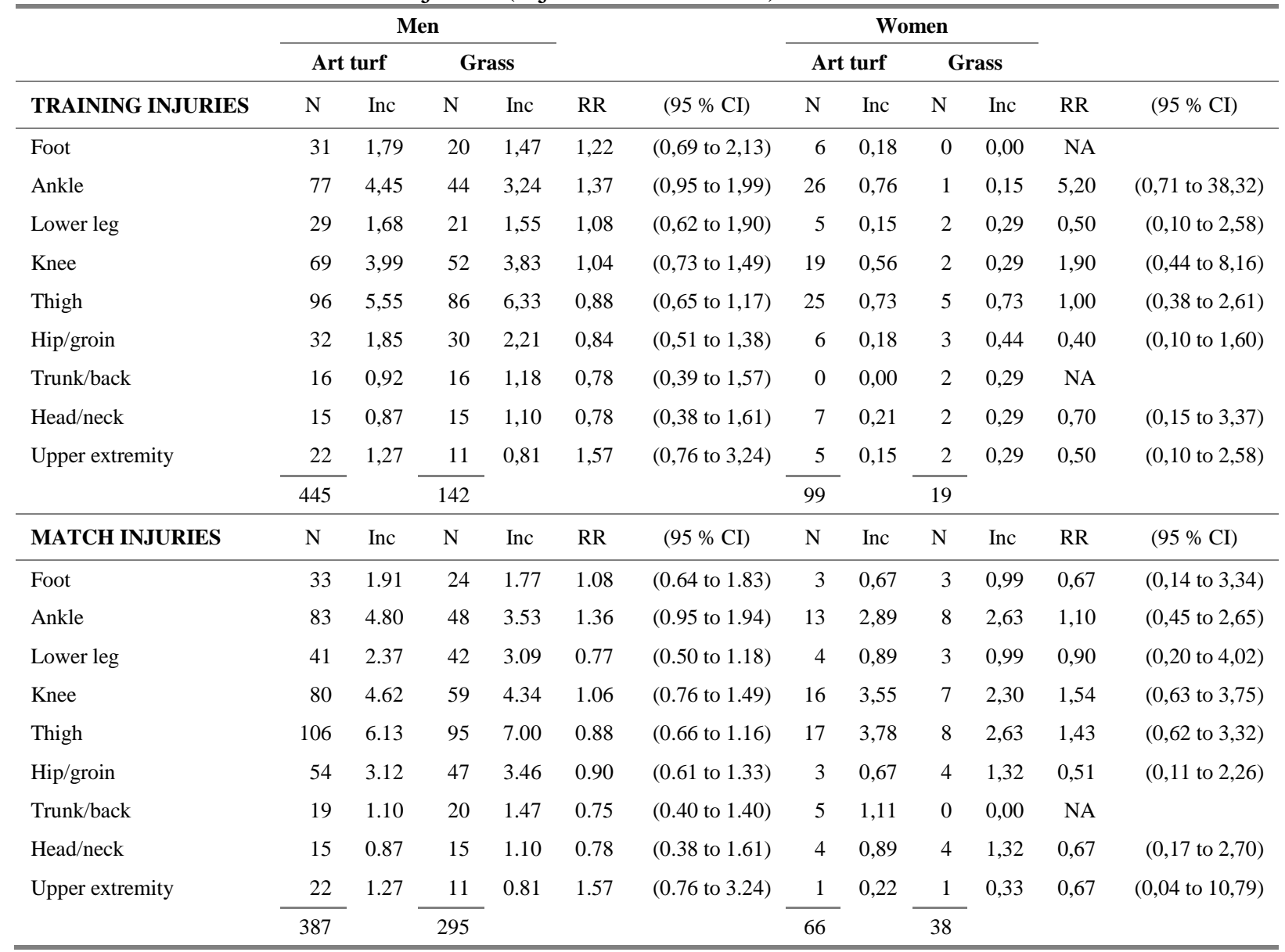

RR: Rate Ratio

Men: 143571 hours on artificial turf (126 272 training and 17299 match play) and 54500 hours on grass (40 921 training and 13579 match play)

Women: 38555 hours on artificial turf (34053 training and 4502 match play) and 9849 hours on grass (6 811 training and 3038 match play).

Overuse injuries $(522 / 1791=29 \%$ in men and $91 / 314=29 \%$ in women $)$ were excluded from the analysis. 
Playing elite level football on artificial turf

Table 6. Incidence of acute injuries (injuries/1000 hours) as a function of the type of injury

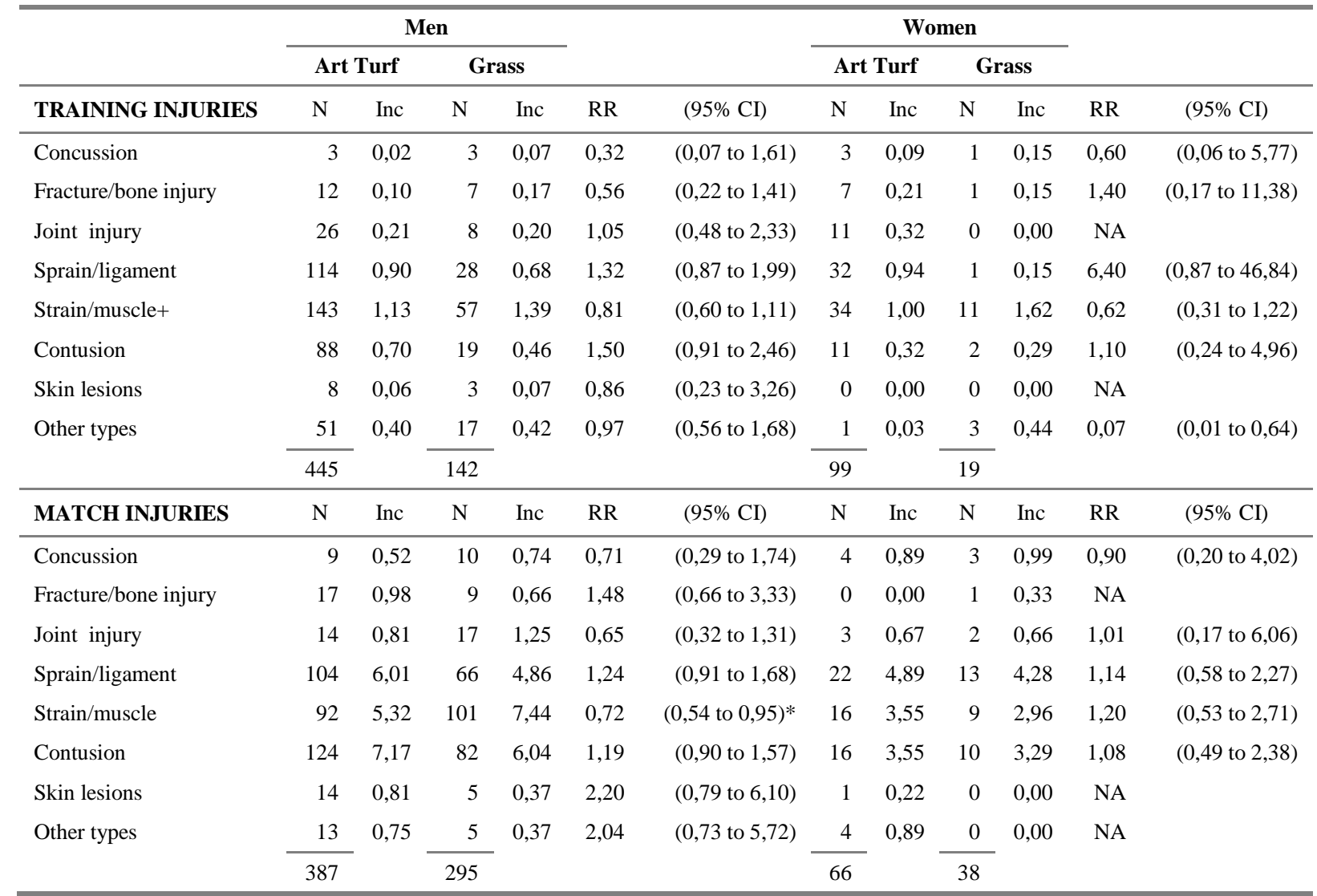

RR: Rate Ratio

$* \mathrm{p}<0.05$

+ Excluding contusions

Men: 143571 hours on artificial turf (126 272 training and 17299 match play) and 54500 hours on grass (40 921 training and 13579 match play)

Women: 38555 hours on artificial turf (34053 training and 4502 match play) and 9849 hours on grass (6 811 training and 3038 match play)

Overuse injuries $(522 / 1791=29 \%$ in men and $91 / 314=29 \%$ in women $)$ were excluded from the analysis. 
Table 7. Incidence of acute injuries (injuries/1000 hours) of most common traumatic injury sub-types (according to Orchard diagnoses)

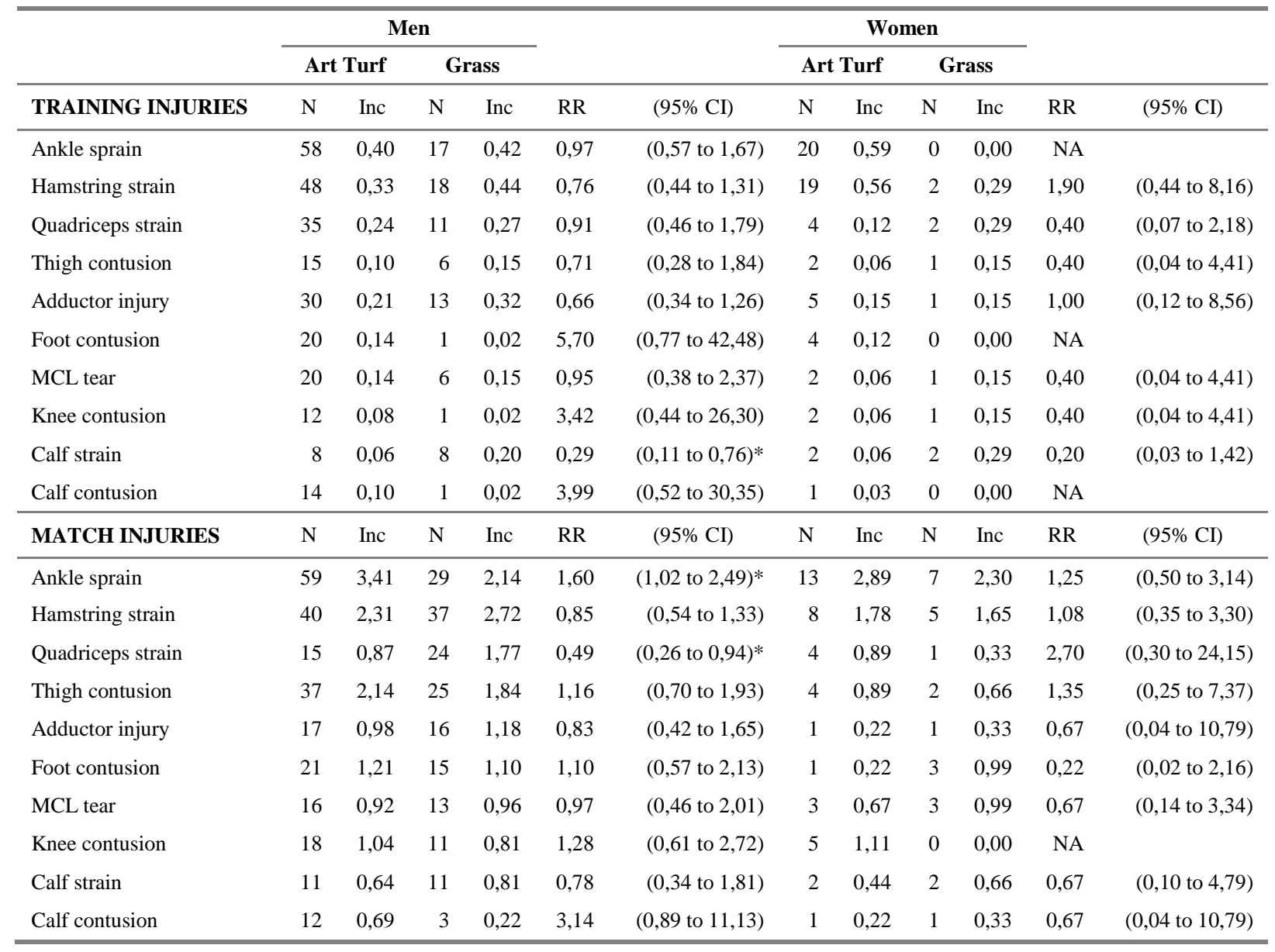

RR: Rate Ratio

$* \mathrm{p}<0.05$

Men: 143571 hours on artificial turf (126 272 training and 17299 match play) and 54500 hours on grass (40 921 training and 13579 match play)

Women: 38555 hours on artificial turf (34053 training and 4502 match play) and 9849 hours on grass (6 811 training and 3038 match play).

Overuse injuries $(522 / 1791=29 \%$ in men and $91 / 314=29 \%$ in women $)$ were excluded from the analysis 
Playing elite level football on artificial turf

Figure 1. Incidence (injuries/1000 hours) of most common overuse injury sub-types (according to Orchard diagnoses)

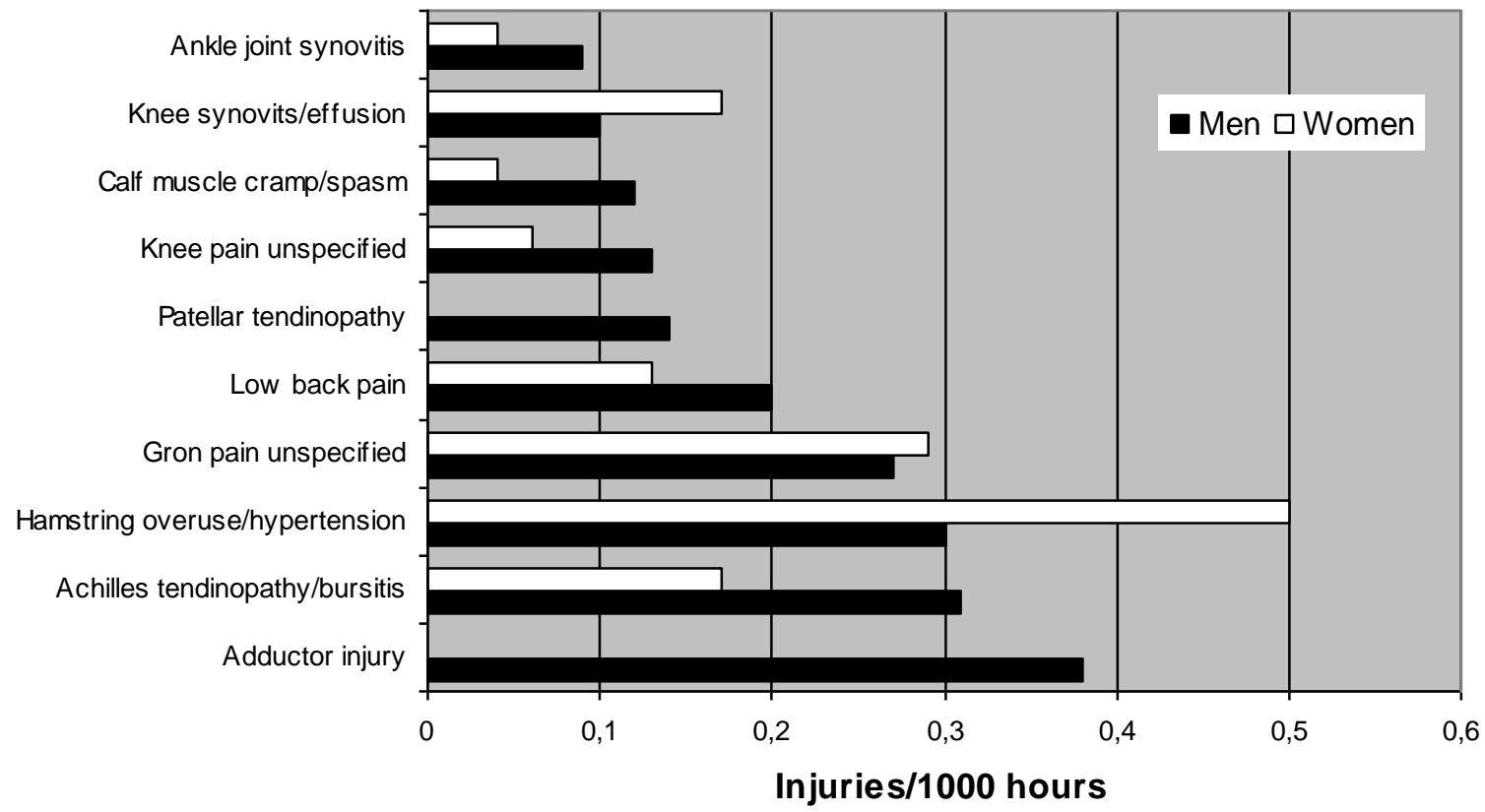

Overuse injuries: men 522/1791=29\% and women 91/314=29\%

Total exposure: men 198071 hours, women 48404 hours 


\section{REFERENCES}

Andersen TE, Floerenes TW, Arnason A, Bahr R. Video analysis of the mechanisms for ankle injuries in football. Am J Sports Med. 2004: 32: 69S-79S.

Andersson H, Ekblom B, Krustrup P. Elite football on artificial turf versus natural grass: movement patterns, technical standards, and player impressions. J Sports Sci. 2008: 26: 113122.

Árnason Á, Gudmundsson Á, Dahl HA, Jóhannsson E. Soccer injuries in Iceland. Scand J Med Sci Sports. 1996: 6: 40-45.

Bahr R. No injuries, but plenty of pain? On the methodology for recording overuse symptoms in sports. Br J Sports Med. 2009: 43: 966-972.

Bahr R, Holme I. Risk factors for sports injuries - a methodological approach. Br J Sports Med. 2003: 37: 384-392.

Bradford-Hill A. The environment and disease: association or causation? Proceedings of the Royal Society of Medicine 1965: 38: 295-300

Dick RW. Is there a gender difference in concussion incidence and outcomes? Br J Sports Med. 2009: 43 Suppl 1: i46-50.

Ekstrand J. Epidemiology of football injuries. Science \& Sports. 2008: 23: 73-77.

Ekstrand J, Gillquist J. The avoidability of soccer injuries. Int J Sports Med. 1983: 4: 124128.

Ekstrand J, Hagglund M, Walden M. Injury incidence and injury patterns in professional football - the UEFA injury study. Br J Sports Med Published Online First: 23 June 2009 doi:10.1136/bjsm.2009.060582

Ekstrand J, Karlsson J, Hodson A. Football Medicine. London: Martin Dunitz (Taylor \& Francis Group) 2003: 562.

Ekstrand J, Nigg BM. Surface-related injuries in soccer. Sports Med. 1989: 8: 56-62.

Ekstrand J, Timpka T, Hagglund M. Risk of injury in elite football played on artificial turf versus natural grass: a prospective two-cohort study. Br J Sports Med. 2006: 40: 975-980. Ekstrand J, Waldén M, Hägglund M. A congested football calendar and the wellbeing of players: correlation between match exposure of European footballers before the World Cup 2002 and their injuries and performances during that World Cup. Br J Sports Med. 2004: 38: 493-497.

Engebretsen L, Kase T. [Soccer injuries and artificial turf]. Tidsskr Nor Laegeforen. 1987: 107: 2215-2217.

FIFA, ed. Laws of the game: FIFA, Zürich, 2009.

Fuller CW, Dick RW, Corlette J, Schmalz R. Comparison of the incidence, nature and cause of injuries sustained on grass and new generation artificial turf by male and female football players. Part 1: match injuries. Br J Sports Med. 2007a: 41 Suppl 1: i20-26.

Fuller CW, Dick RW, Corlette J, Schmalz R. Comparison of the incidence, nature and cause of injuries sustained on grass and new generation artificial turf by male and female football players. Part 2: training injuries. Br J Sports Med. 2007b: 41 Suppl 1: i27-32.

Fuller CW, Ekstrand J, Junge A, Andersen TE, Bahr R, Dvorak J, Hagglund M, McCrory P, Meeuwisse WH. Consensus statement on injury definitions and data collection procedures in studies of football (soccer) injuries. Br J Sports Med. 2006: 40: 193-201.

Gaulrapp H, Siebert C, Rosemeyer B. [Injury and exertion patterns in football on artificial turf]. Sportverletz Sportschaden. 1999: 13: 102-106.

Hägglund M, Walden M, Ekstrand J. Injury incidence and distribution in elite football--a prospective study of the Danish and the Swedish top divisions. Scand J Med Sci Sports. 2005: 15: 21-28. 
Hägglund M, Walden M, Ekstrand J. Injuries among male and female elite football players. Scand J Med Sci Sports.2008:19:819-827.

Hawkins RD, Hulse MA, Wilkinson C, Hodson A, Gibson M. The association football medical research programme: an audit of injuries in professional football. Br J Sports Med. 2001: 35: 43-47.

Hort W. Behandlung von schäden auf konststoffboden. BISP Köln. 1977: 9: 176-181.

Hägglund M, Waldén M, Bahr R, Ekstrand J. Methods for epidemiological study of injuries to professional football players: developing the UEFA model. Br J Sports Med. 2005: 39: 340346.

Junge A, Dvorak J. Injuries in female football players in top-level international tournaments. Br J Sports Med. 2007: 41 Suppl 1: i3-7.

Meeuwisse WH. Assessing causation in sport injury: a multfactorial model. Clinical Journal of Sport Medicine. 1994: 4: 166-170.

Nigg BM, Yeadon MR. Biomechanical aspects of playing surfaces. J Sports Sci. 1987: 5: 117-145.

Renström P, Peterson L, Edberg B. Valhalla artificial pitch at Gothenburg 1975-1977, a twoyear evaluation.: Naturvårdsverket, Sweden, 1977.

Steffen K, Andersen TE, Bahr R. Risk of injury on artificial turf and natural grass in young female football players. Br J Sports Med. 2007: 41 Suppl 1: i33-37.

Walden M, Hagglund M, Ekstrand J. Injuries in Swedish elite football--a prospective study on injury definitions, risk for injury and injury pattern during 2001. Scand J Med Sci Sports. 2005: 15: 118-125.

Walden M, Hagglund M, Ekstrand J. UEFA Champions League study: a prospective study of injuries in professional football during the 2001-2002 season. Br J Sports Med. 2005: 39: 542546.

Walden M, Hagglund M, Ekstrand J. Football injuries during European Championships 20042005. Knee Surg Sports Traumatol Arthrosc. 2007: 15: 1155-1162. 